\title{
WORK RELATED RISK FACTORS AND PREGNANCY OUTCOME BETWEEN WORKING WOMEN
}

\author{
By \\ ${ }^{1}$ Hathout HM, ${ }^{1}$ El-Dalatony MM, ${ }^{2}$ Anwar MM, \\ ${ }^{1} \mathrm{Al}$-Batanony MA and ${ }^{3}$ Shehata NA. \\ ${ }^{1}$ Department of Public Health and Community Medicine, Faculty of Medicine, Menoufiya University. \\ ${ }^{2}$ Department of Public Health and Community Medicine, \\ ${ }^{3}$ Department of Obstetric and Gynecology, Faculty of Medicine, Beni-Suef University.
}

\begin{abstract}
:
Introduction: The employment rate of mothers has increased worldwide in recent years. So, there is concern about possible effects of work related risk factors and pregnancy outcome among working women. Aim of Work: To study the relation between work related risk factors and some adverse pregnancy outcome among a representative sample of pregnant women attending the antenatal care clinic at BeniSuef university hospital in Egypt. Materials and Methods: 500 pregnant women who were visiting the antenatal care clinic at Beni-suef university hospital were our target group. They were interviewed using predesigned questionnaire including physical activity questionnaire, Job Stress Questionnaire, Workplace Stress Survey. Body mass index (BMI) is measured. Statistical analysis performed using SPSS version 21. Results: Among studied socio-demographic factors, age and educational level and body mass index were significantly associated with adverse pregnancy outcomes. Perinatal death was significantly higher among working women (odds ratio $=1.9, \mathrm{CI}=$ 101-3.8). Among studied working conditions, working more than 40 hours/ week was significantly associated with high rate of preterm delivery and small gestational age (SGA) increase significantly with high work stress. Conclusion: Among the studied work conditions for working women, working more than 40 hours/ week and social stress index were found to be a significant risk factors for adverse pregnancy outcomes. Other factors as shift work, work categories, and physical activity score showed no significant association with pregnancy outcomes. Therefore, as long as the health of pregnant women permits her to continue work during pregnancy that is not stressful or overloading for her, no adverse effect on pregnancy outcomes is expected.
\end{abstract}

Key words: Pregnancy outcome, Shift work, Small for gestational age SGA, Perinatal death, Preterm. 


\section{Introduction}

The potential impact of employment on pregnancy is an important issue due to the increasing number of woman entering the labor force and continuing employment throughout pregnancy (Arafa and Abdel Fattah, 2007).

The majority of women remain well through their pregnancy. So, pregnancy should not be considered as either an illness, or a contraindication for work. However, a working pregnant woman may be exposed to particular hazards that might potentially cause adverse pregnancy outcome for her or her fetus (Royal College of physicians, 2009)

A meta-analysis has shown that physically demanding work that includes prolonged standing, shift and night work, and a high cumulative work fatigue score may be associated with adverse pregnancy outcomes such as spontaneous abortion, stillbirth, or low birth weight. Occupational exposures may also, interact with the fetal development, resulting in illhealth effects in the offspring, such as congenital malformations and neurobehavioral disorders in childhood (Mozurkewich et al.,2000).
The significant work factors directly correlated with adverse pregnancy outcomes included: fewer household helpers, standing at work for more than 7 hours per day, working in hot environments, commuting, walking, and carrying and lifting heavy weight (Banerjee , 2009)

Study of another systematic review reported that shift work, lifting an object at work, and prolonged standing might lead to pre-term delivery (Bonzini et al., 2007)

Physical exertion has been suggested as a risk factor for adverse pregnancy outcome due to the combined effects of vasoconstriction, myometrial contraction, reduced plasma volume, and diversion of blood flow away from the placental bed, diminution of uteroplacental blood flow with resultant fetal hypoxia. This, along with possible hormonal imbalance, may have deleterious effects on the fetus (Banerjee, 2009) .

Despite the probability that working women may have less favorable pregnancy outcomes, some studies of the health among working women provide conflicting results and leave the issue unresolved. Moreover, only few such studies have been conducted 
in the developing countries (Arafa and Abdel Fattah, 2007), which necessitates further study to clarify these issues.

\section{Aim of Work}

To study the relation between work related risk factors and some adverse pregnancy outcome among a representative sample of pregnant women attending the antenatal care clinic at Beni-Suef university hospital in Egypt.

\section{Materials and Methods}

A prospective study involved 500 pregnant women who were visiting the antenatal care clinic at Beni-Suef University hospital, Egypt during the year 2013. The target group were enrolled in the study during their first antenatal care visit after taking their written consent to participate in the study. The purpose of study was explained to all of them and all were followed up until delivery.

\section{Tools of study:}

\section{Predesigned questionnaire :}

All participants were interviewed by trained personnel using a predesigned questionnaire that included the following data:
I. Personal information: age at this first antenatal care visit, educational level, Special habits, contact information.

II. Obstetric history: duration of pregnancy at first antenatal care visit, expected date of delivery, history of present and past conceptions if any. Number of children, history of abortion, still birth or low birth weight

III. Occupational history: for working participants, work characteristics were included in details:-Type of work,number of working hours/ day, work pattern (daytime work or shift work), duration of work in years, working days/week, prolonged physical strain or fatigue, exposure to potential occupational hazards as radiation, chemical exposure, biological agents.

Work categories: Type and nature of work was then categorized into 5 main groups (Clerical workers, Elementary occupations, Health Professionals, Teaching Professionals, Technicians) according to (International Standard Classification of Occupations (ISCO), 2008). 
IV. Medical history: history of Diabetes Mellitus, cardiac diseases, medications---etc. which may affect the outcome of pregnancy were excluded from the study.

V. Adverse pregnant outcomes:-The main outcomes assessed during follow up included :

i. Perinatal death (abortion, still birth or early neonatal deaths),

ii. Preterm delivery (delivery of the fetus before 37 completed week of gestation),

iii. Small for gestational age (SGA) :(birth weight below the 10th for a given gestational age) (Lawrence, 2006).

Pregnancy outcome was assessed during follow up of participating women in the sequential antenatal care visits (via ultrasound and other investigations) and after delivery. For women delivering outside the hospital, the outcome was obtained by contact information.

\section{Physical activity questionnaire:-}

General Practice Physical Activity Questionnaire (GPPAQ) was used as a validated short measure of physical activity based on type and amount of physical activity involved during work. It generates a simple - 4-level Physical Activity Index (PAI) - categorizing subjects as: Active, Moderately Active, Moderately Inactive, and Inactive) The General Practice Physical Activity Questionnaire (GPPAQ), 2006).

\section{The Job Stress Questionnaire:-}

Load of stress encountered during work measured using (Workplace Stress Survey of The American Institute Of Stress (AIS), 2011).

\section{Workplace Stress Survey :}

AIS has created a job stress survey that can help reveal employee stress levels. Survey participants are asked to assign a number from one to 10 statements that describe amount of work stress and work satisfaction.

According to this questionnaire, three levels of work stress were identified:-

- $\quad$ Mild stress (A score of 10-30)

- Moderate stress (A score of 4060)

- Severe stress (A score of 70100)

5. Body Mass Index (BMI) was calculated from the formula: prepregnant weight in kilos/(height in 
meter)2, then according to (WHO, integrity, names of the participant were 2012) classification of BMI the kept confidential.

women classified into 4 Categories underweight $\quad(\mathrm{BMI}=15-18.5)$,

Normal weight (BMI= 18.5- 24.9), Overweight $\quad(\mathrm{BMI}=$ 25-29.9),

Obese $(\mathrm{BMI}=\geq 30)$.

Consent: an informed consent was taken from all the participants.

\section{Ethical approval} To ensure privacy, dignity and considered significant.

\section{Data analysis:-}

Data was tabulated and statistically analyzed using SPSS version 21 , chi square test and Odds ratio were used to study the association between work related risk factors and studied pregnancy outcomes. $\mathrm{P}$ value $<0.05$ was

\section{Results}

Table 1:- Socio-demographic characteristics of the studied participants

\begin{tabular}{|c|c|c|c|c|c|}
\hline \multirow[t]{2}{*}{$\begin{array}{l}\text { Socio-demographic } \\
\text { characteristics }\end{array}$} & \multicolumn{2}{|c|}{$\begin{array}{c}\text { Non-working } \\
\text { women } \\
\mathbf{N}=\mathbf{3 2 6}\end{array}$} & \multicolumn{2}{|c|}{$\begin{array}{l}\text { Working } \\
\text { women } \\
\mathrm{N}=174\end{array}$} & \multirow[t]{2}{*}{$P$ value } \\
\hline & No. & $\%$ & No. & $\%$ & \\
\hline $\begin{array}{l}\text { Age categories:- } \\
<20 \text { years } \\
20-35 \text { Years } \\
>35 \text { Years } \\
\end{array}$ & $\begin{array}{l}55 \\
242 \\
29\end{array}$ & $\begin{array}{l}16.9 \\
74.2 \\
8.9 \\
\end{array}$ & $\begin{array}{l}4 \\
152 \\
18\end{array}$ & $\begin{array}{l}2.3 \\
87.4 \\
10.3 \\
\end{array}$ & $\begin{array}{c}0.0001 * \\
0.02 * \\
0.8 \\
\end{array}$ \\
\hline $\begin{array}{l}\text { Residence } \\
\text { Rural } \\
\text { Urban } \\
\end{array}$ & $\begin{array}{l}258 \\
68 \\
\end{array}$ & $\begin{array}{l}79.1 \\
20.9 \\
\end{array}$ & $\begin{array}{l}78 \\
96 \\
\end{array}$ & $\begin{array}{l}44.8 \\
55.2 \\
\end{array}$ & $0.000^{*}$ \\
\hline $\begin{array}{l}\text { Educational level } \\
\text { Illiterate/ basic } \\
\text { Secondary and higher }\end{array}$ & $\begin{array}{l}180 \\
146\end{array}$ & $\begin{array}{l}55.2 \\
44.8\end{array}$ & $\begin{array}{l}36 \\
138\end{array}$ & $\begin{array}{l}20.7 \\
79.3\end{array}$ & $0.000^{*}$ \\
\hline $\begin{array}{l}\text { BMI } \\
\text { Underweight } \\
\text { Normal } \\
\text { Overweight / Obese }\end{array}$ & $\begin{array}{l}26 \\
178 \\
122 \\
\end{array}$ & $\begin{array}{l}7.9 \\
54.6 \\
36.5 \\
\end{array}$ & $\begin{array}{l}12 \\
92 \\
70\end{array}$ & $\begin{array}{l}6.9 \\
52.9 \\
40.2\end{array}$ & $\begin{array}{l}0.7 \\
0.7 \\
0.6\end{array}$ \\
\hline
\end{tabular}

*: Significant

Comparison of the socio-demographic characteristics showed a significant difference between working women aged 20-35 years, residing in urban areas with high education level (secondary to university) compared to non-working ones. 


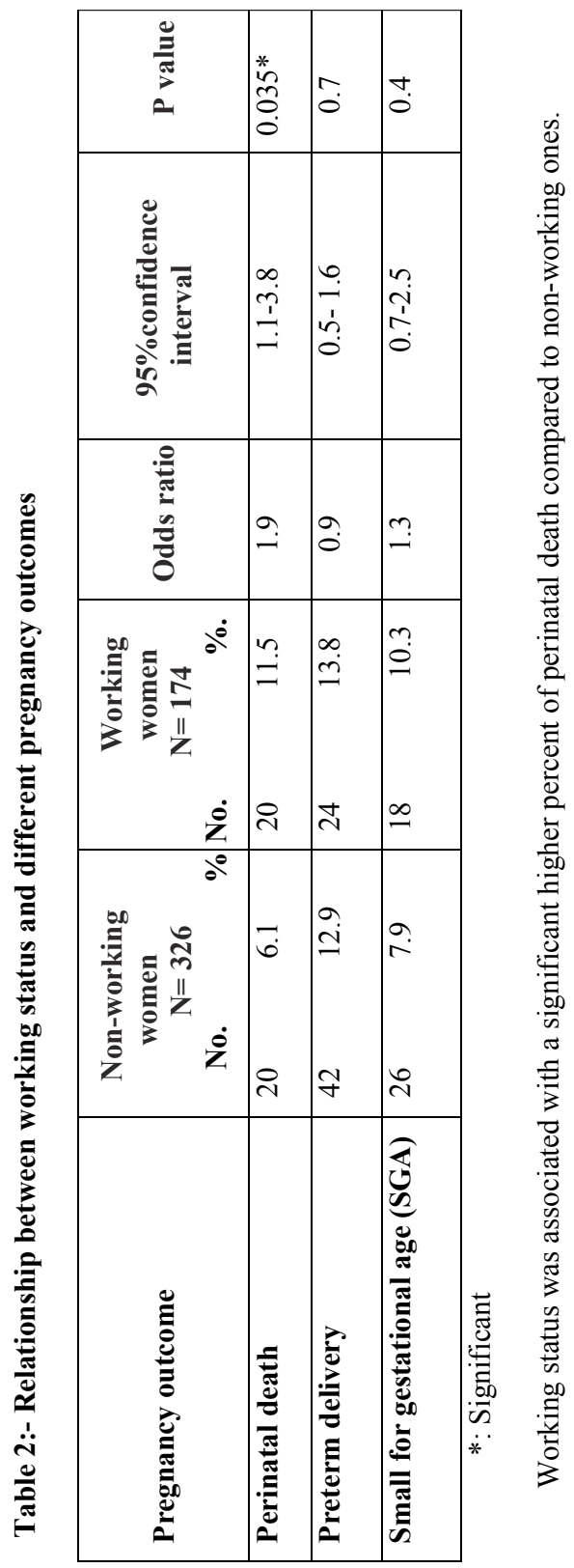









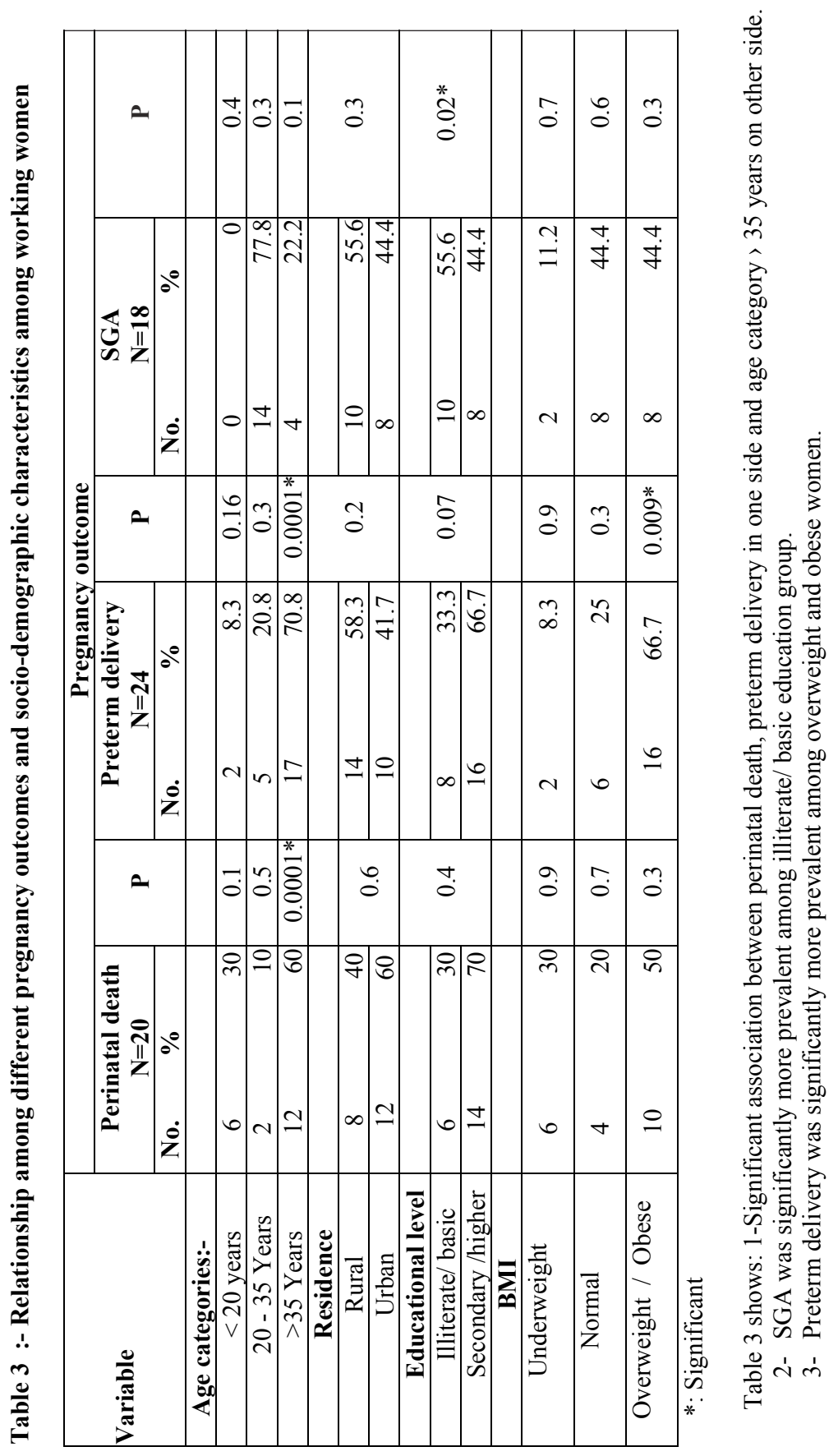




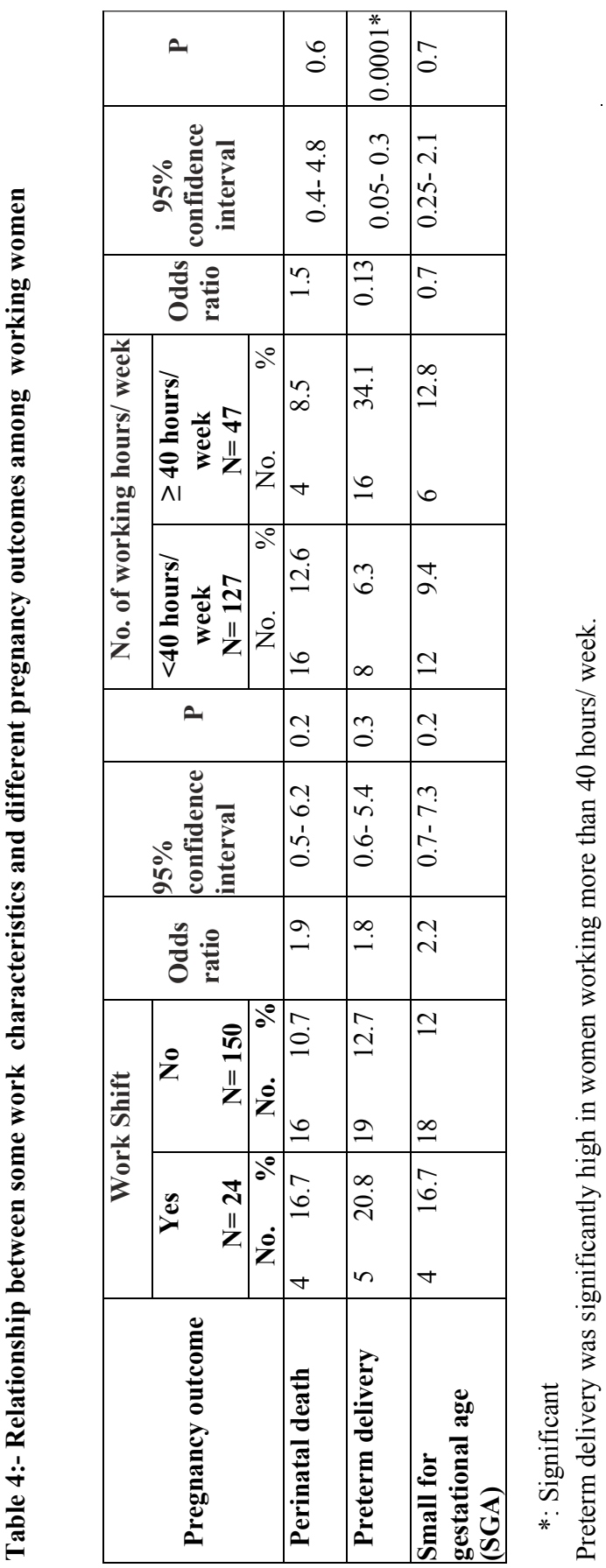


Hathout HM et al.,

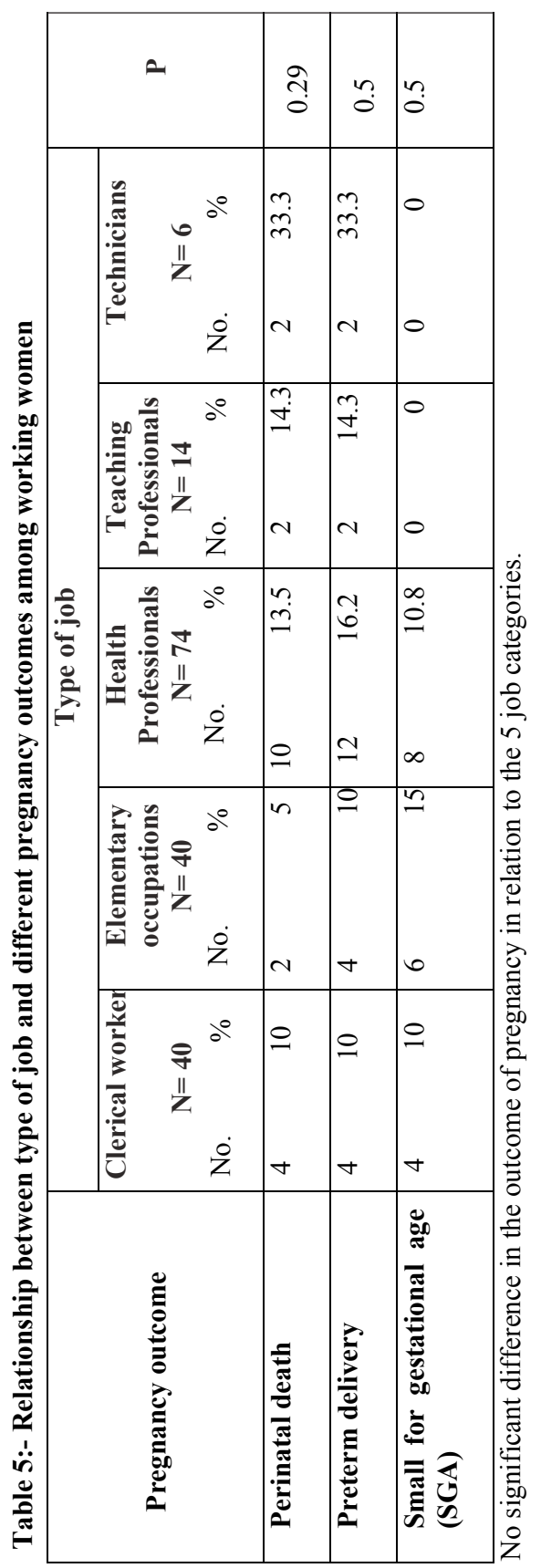




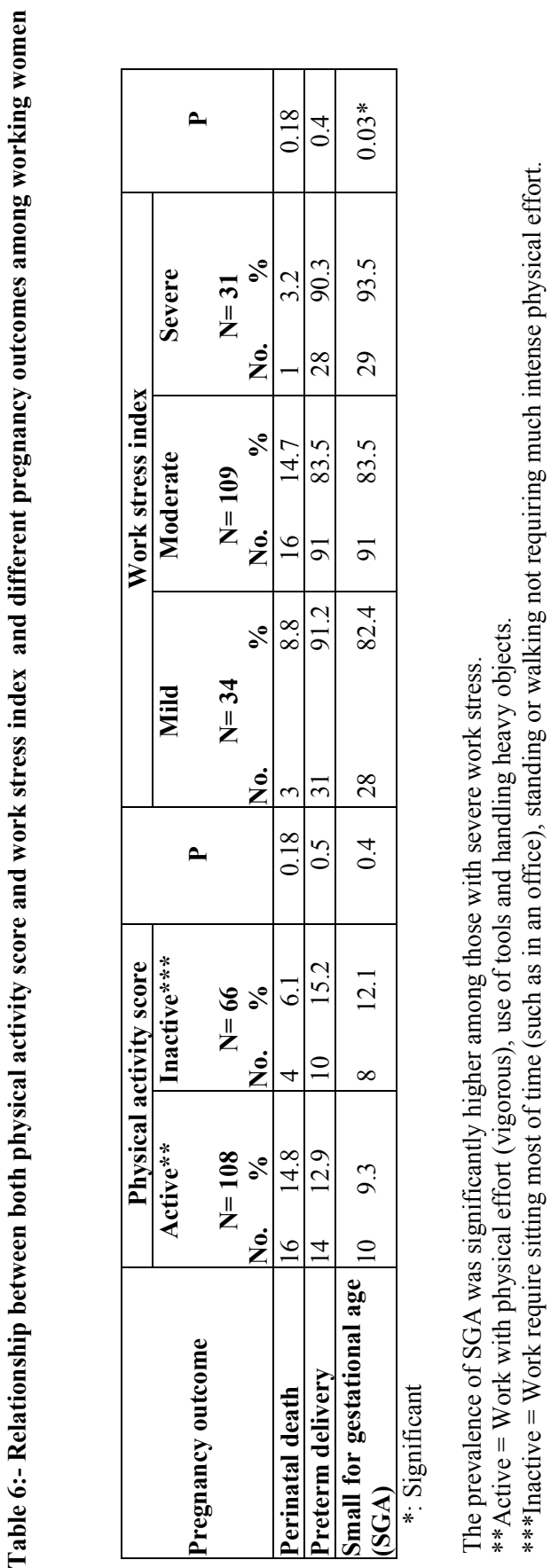




\section{Discussion}

This prospective study involved 500 pregnant women who attended the antenatal care clinic at Beni-Suef university hospital, Egypt during the year 2013. Of which, 174 women were working full time during pregnancy. Most of the working women (87\%) were in the age categories between 20 35 years with educational level ranging between secondary and university education (42\%\& 37\%; respectively) (table 1).

There was a significant difference for the age categories, residence, and educational level between working and non-working women, showing a higher percentage of non-working women < 20 years of age, compared to higher percent of 20-35 years age category for working women. For residency, most of non-working women resided in rural areas (80\%) compared to $45 \%$ for working subjects. Most working women (79\%) have secondary / higher education compared to $45 \%$ amongst the non-working ones; a finding which is consistent with the reported high percentages of educational level for working women (Arafa and Abdel Fattah, 2007) and (Niedhammer et al., 2009).
Peri-natal death was reported in $11.5 \%$ vs. $6 \%$ for working compared to non-working subjects $(\mathrm{p}=0.035)$ (Table $2)$. This finding is consistent with that of (Banerjee , 2009) who found an increase in the perinatal mortality rate among employed women with reported significant work factors that correlated with miscarriage and/or perinatal death included: fewer household helpers, standing, working in hot environment, walking, carrying, and lifting heavy weight at work (Banerjee , 2009). No significant difference was observed in preterm delivery and SGA between working and non-working women (Table 2); a finding which is similar to that reported (Arafa and Abdel Fattah, 2007) indicating that working to term in absence of contraindications did not impose any added risk to the mother or infant.

The risk of preterm delivery and perinatal death was significantly higher among the age group more than 35 years of age (table3), a finding that coincides with the study of (Louise et al ., 2013) who reported that older mothers are at increased risk of adverse pregnancy outcome compared to their younger counterparts. 
Moreover among working women, it was observed that the prevalence of SGA was significantly higher among women with low education (illiterate/ basic) (Table 3 ).

Relation between educational level and outcomes of pregnancy has been described many decades ago with inverse relation between pregnancy outcomes and maternal education. Higher education not only presumes higher economic standing but suggests a more informed approach to both self-care and the use of the health care system. Better knowledge of healthrelated behaviors is also likely to be reflected by the woman's education level (Morrison et al., 1989).

In this study the preterm delivery was significantly high among obese and overweight women, in agreement to that reported by (Sebire et al., 2001) and (Cedergren , 2004) who found that maternal obesity carried significant risk for the mother and fetus.

Studying working characteristics in relation to pregnancy outcomes, there was significant high prevalence of preterm delivery in women working more than 40 hours/ week during pregnancy. This is similar to finding of other European studies that detect a moderate excess risk of preterm birth and small-for-gestational-age for pregnant women employed as manual workers and for those working $>40 \mathrm{hrs} /$ week, or standing for long period (Cubizolles et al ., 2004), (Niedhammer et al., 2009) ,(Mozurkewich et al.,2000), (Nurminen , 1998), (Pompeii et al., 2005), (Zhu et al ., 2004), (Croteau et al ., 2007) and (Tuntiseranee et al ., 1998)

There was no significant difference in pregnancy outcome in relation to shift work, or different job categories (table 4, table 5), which is in agreement with reported data from (Cubizolles et al ., 2004) and (Henriksen et al ., 1994) indicating that work would not have a detrimental effect on pregnancy outcomes so long as pregnant women are in good health.

Small for gestational age is significantly high with severe work stress index (table 6); and this finding supported by (Lee et al., 2011). A possible biological mechanism linking maternal stress and birth outcomes indicates that stress triggers the production of placental corticotrophin releasing hormone $(\mathrm{CRH})$, which in turn results in reduced gestational age and low birth weight (Hobel and Culhane, 2003) and (Lockwood , 1999). 


\section{Conclusion}

This prospective study was planned to demonstrate the relationship between different work characteristics and three of pregnancy outcomes including perinatal death, preterm delivery, and small for gestational age. A Significant relationship was detected between working status and prenatal death. Socio-demographic factors found to affect pregnancy outcomes including older maternal age and low educational level, and high body mass index. Among the studied working conditions, working more than 40 hours/ week and work stress index were significantly associated with high rate of SGA.

\section{Conflict of interest:}

Authors have declared that no conflict of interests exists.

\section{No financial support}

\section{References}

1. Arafa M, Amine $T$ and Abdel Fattah $M$ (2007): Association of Maternal Work with Adverse Perinatal Outcome. Canadian journal of public health ; 98 (3): 217-21

2. Banerjee B (2009): Physical Hazards in Employment and Pregnancy Outcome. Indian Journal of Community Medicine; 34 (2): 89-93.

3. Bonzini M, Coggon D and Palmer T (2007): Risk of prematurity, low birth weight, and preeclampsia in relation to working hours and physical activities: a systematic review. Occup Environ Med; 64: 228-43.
4. Cedergren M (2004): Maternal Morbid obesity and the risk of adverse pregnancy outcome. American college of obstetricians and gynecologists; 103(2):219-24.

5. Croteau A, Marcoux S and Brisson C (2007): Work activity in pregnancy, preventive measures, and the risk of preterm delivery. Am J Epidemiol; 166:951-65.

6. Cubizolles SM, Zeitlin J, Lelong N, Papiernik E, Di Renzo GC , Breart G et al. (2004): Employment, working conditions, and preterm birth: Results from the European Case Control Survey. J Epidemiol Community Health; 58 (5): 395-401.

7. Henriksen TB, Savitz DA, Hedegaard M and Secher NJ (1994): Employment during pregnancy in relation to risk factors and pregnancy outcome. $\mathrm{Br} \mathrm{J}$ Obstet Gynecol; 101(10): 858-65.

8. Hobel C and Culhane J (2003): Role of psychosocial and nutritional stress on pregnancy outcome. Journal of Nutrition; 133: 1709S-17S.

9. International Standard Classification of Occupations (ISCO) (The 2008 edition).

10. Lawrence E (2006): Part 1: A matter of size: Evaluating the growth-restricted neonate. Advances in Neonatal Care; 6(6):313-322.

11. Lee BE, Ha M, Park H, Hong YC, Kim Y, Kim YJ, et al. (2011): Psychosocial work stress during pregnancy and birth weight. Paediatr Perinat Epidemiol; 25(3): 246-54.

12. Lockwood CJ (1999): Stress-associated preterm delivery. The role of corticotropin-releasing hormone. American Journal of Obstetrics and Gynecology; 180: S264-S6.

13. Louise C, Lavender T, McNamee R, Sine'ad M. O'Neill and Mills T(2013): “Advanced maternal age and adverse pregnancy outcome". Evidence from a large contemporary cohort"; PLOS one 8: 2 e56583. Available at: http// www.polsone. org 
14. Morrison J, Najman JM, Williams GM, Keeping J D and Andersen M J (1989): SocioEconomic Status and Pregnancy Outcome: An Australian Study. British Journal of Obstetrics and Gynecology; 96 (3): 298-307.

15. Mozurkewich EL, Luke B, Avni M and Wolf FM (2000): Working conditions and adverse pregnancy outcome: A meta-analysis. Obstet Gynecol; 95: 623-35.

16. Niedhammer I, O’Mahony D, Daly S, Morrison J and Kelleher C (2009): Occupational predictors of pregnancy outcomes in Irish working women in the Lifeways cohort; BJOG;116: 943-952.

17. Nurminen $T$ (1998): Shift work and reproductive health. Scand J Work Environ Health; 24 (Suppl 3): 28-34.

18. Pompeii LA, Savitz DA, Evenson KR, Rogers B and McMahon M (2005): Physical exertion at work and the risk of preterm delivery and smallfor-gestational-age birth Obstet Gynecol; 106: 1279-88.

19. Royal college of physicians (2009): Physical and shift work in pregnancy. Occupational aspects of management a national guideline.

20. Sebire NJ, Jolly M, Harris JP, Wadsworth J, Joffe MBeard RW, et al.( 2001): Maternal obesity and pregnancy outcome: a study of 287,213 pregnancies in London. Int J Obes Relat Metab Disord; 25(8):1175-82.

21. The General Practice Physical Activity Questionnaire (GPPAQ) (2006): Dept of health. Available at http://www.dh.gov.uk/ en/Publicationsandstatistics/Publications/ PublicationsPolicyGuidance/DH_063812.

22. Tuntiseranee $\mathrm{P}$, Geater A, Chongsuvivatwong V and Kor-anantakul O (1998): The effect of heavy maternal workload on fetal growth retardation and preterm delivery. A study among southern Thai women. J Occup Environ Med; 40:1013-21.

23. World Health Organization (WHO) (2006): "BMI" Global Database on Body Mass Index. Retrieved July 27, 2012.

24. Workplace Stress Survey of The American Institute Of Stress (AIS) (2011): (http:// www.stress.org/wp-content/uploads/2011/08/ Workplace-Stress-Survey.pdf)

25. Zhu JL, Hjollund NH and Olsen J (2004): Shift work, duration of pregnancy, and birth weight: the National Birth Cohort in Denmark. Am J Obstet Gynecol; 191:285-91. 